\title{
CLINICAL OUTCOME OF PATIENTS ADMITTED WITH ACUTE ANTERIOR VERSUS ACUTE INFERIOR WALL MYOCARDIAL INFARCTION
}

\author{
Moazzam Khan, Imtiaz Ahmed Khan, Naseer Ahmad Samore, Javeria Kamran, Anam Fatima Janjua, Ahmed Mustafa, \\ Rashid Iqbal, Usman Ahmed, Fiaz Ahmed*, Sohail Aziz \\ Armed Forces Institute of Cardiology/National Institute of Heart Disease (AFIC/NIHD)/National University of Medical Sciences (NUMS) \\ Rawalpindi Pakistan, *DHQ Hospital Abbottabad Pakistan
}

\begin{abstract}
Objective: To determine the clinical outcome of patients admitted with acute anterior versus acute inferior wall myocardial infarction.

Study Design: Comparative cross-sectional study.

Place and Duration of Study: The study was conducted in emergency departments and adult cardiology wards of Armed Forces Institute of Cardiology/National Institute of Heart Diseases, from Aug 2019 to Nov 2019.

Methodology: This study was conducted on 340 patients (208 patients with Anterior wall myocardial infarction and 132 patients with inferior wall MI who presented with Acute ST-Elevation MI) to emergency department of Armed Forces Institute of Cardiology/National Institute of Heart Disease during specified period. Outcome was calculated using Electrocardiogram, Two-dimensional transthoracic echocardiogram, Troponin-I, baseline investigations and coro angiography Data was entered and analyzed with SPSS-23.

Results: Mean age was $59.38 \pm 12.91$ years in each group. In clinical symptoms chest pain was highest $\mathrm{n}=255$ $(71.4 \%)$ followed by diaphoresis $55(15.4 \%)$ and breathlessness $51(14.3 \%)$. The most common complications in patients with inferior wall MI were brady arrhythmia $8(2.3 \%)$ whereas left ventricular failure $41(12.1 \%)$ was more prevalent in patients with anterior wall MI after TVCAD. The results of cardiogenic shock $5(1.5 \%)$, ventricular tachycardia $3(0.8 \%)$ in inferior wall myocardial infarction were comparative to the results of cardiogenic shock $18(5.3 \%)$ ventricular tachycardia $2(0.5 \%)$ in anterior wall myocardial infarction. The number of stable patients was 91 (43.7\%) in Anterior wall myocardial infarction and 51 (38.6\%) in inferior wall MI.

Conclusion: The study shows the comparative clinical outcome of anterior wall myocardial infarction versus inferior wall myocardial infarction.
\end{abstract}

Keywords: Acute anterior myocardial infarction, Acute inferior wall myocardial infarction, Clinical outcome.

This is an Open Access article distributed under the terms of the Creative Commons Attribution License (http://creativecommons.org/licenses/by/4.0), which permits unrestricted use, distribution, and reproduction in any medium, provided the original work is properly cited.

\section{INTRODUCTION}

Coronary artery disease (CAD) is one of the most common causes of morbidity and mortality, particularly in developing countries such as Pakistan. Although age-adjusted mortality from myocardial infarction is gradually falling in developed countries, the death rate is increasing in Pakistan 1 . It is believed that changing lifestyles such as high consumption of processed foods rich in saturated fat and a low level of physical activity are leading to a progressive increase in the prevalence of $\mathrm{MI}$ and its risk profile ${ }^{2}$. Acute ST segment elevation myocardial infarction (MI) usually occurs when a thrombus is formed as

Correspondence: Dr Moazzam Khan, Cardiology Dept, AFIC/ NIHD Rawalpindi Pakistan result of a ruptured atheromatous plaque and occludes the epicardial coronary artery ${ }^{3}$. AMI is defined as rapid myocardial necrosis due to supply/demand mismatch ${ }^{3}$. Patient survival depends on several factors, the most important being the restoration of antegrade coronary flow ${ }^{4}$. The major goal of reperfusion therapy is to minimize the time during which the culprit coronary artery remains occluded by rapidly achieving high quality reperfusion at both the epicardial and microcirculatory level, and to prevent re-occlusion after initially successful fibrinolysis. The two main methods of reopening an occluded artery are: (1) primary percutaneous transluminal coronary angioplasty (PTCA) with stent implantation; and (2) pharmacological reperfusion with administration of fibrinolytic therapy ${ }^{4}$. In the clinical 
assessment of chest pain, electrocardiography is an essential adjunct to the clinical history and physical examination. A rapid and accurate diagnosis in patients with acute MI is vital. The most frequently used electro-cardiographic criterion for identifying acute MI is ST segment elevation in two or more anatomically contiguous leads ${ }^{4}$. Following the American College of Cardiology guidelines, fibrinolytic therapy should be administered to ST elevation myocardial infarction (STEMI) patients with symptom onset within 12 $\mathrm{h}$, or in some circumstances up to $24 \mathrm{~h}$, and ST elevation $>0.1 \mathrm{mV}$ in at least two contiguous precordial leads or at least two adjacent limb leads. The early and accurate identification of the infarct related artery on the electrocardiogram (ECG) can help predict the amount of myocardium at risk and guide decisions regarding the urgency of revascularization 4 . Despite the importance of determining correlates of the severity and extension of infarction, the role of some factors such as location of cardiac ischemia for predicting coronary artery severity and its-related life-threatening events particularly in our population has been already questioned. Several factors have been shown to predict the increased risk for recurrent cardiac events and death after acute myocardial infarction; one of the most important factors includes anterior location of the infarct. This factor can influence the improvement rate of left ventricular ejection fraction and wall motion after the onset of acute myocardial infarction and may be accompanied by different complications and mortality rates in comparison with other types of wall involvement ${ }^{5}$. Some studies compared the prognosis of two common types of inferior and anterior wall myocardial infarction and confirmed that anterior wall infarction were associated with worse complications and higher mortality than inferior. An anterior-wall MI may produce varying degrees of atrioventricular (AV) or fascicular heart block-such as first-degree AV block, type II second-degree AV block, third-degree AV block with ventricular escape, and bundlebranch block. Bradycardia or heart block with anterior wall MI is a poor prognostic sign. Other complications include severe left ventricular dysfunction, resulting in heart failure and cardiogenic shock, ventricular septal rupture, and ventricular free-wall rupture ${ }^{6}$. However, some recent studies have hypothesized that inferior wall myocardial infarction can be associated with a significantly higher risk of mortality than anterior wall and this result has been obtained based on long-term evaluations. It was also found that although patients with initial anterior wall myocardial infarction had a relatively unfavorable early outcome, the late outcome appeared to be unaffected ${ }^{7}$. In addition, it was shown that the site of the infarct can be influenced by early outcomes but not long-term prognosis7, Inferior myocardial infarction causing substantial myocardial damage usually is large and often includes right ventricular involvement, hypotension, bradycardia, heart block, and cardiogenic shock., the factors that influences long-term prognosis 8,9 . However, an important question remains about the differences in the severity and extension of coronary arteries involvement in the two types of inferior and anterior wall infarction. Traditionally, inferior MIs have a better prognosis, than those in other regions, such as the anterior wall of the heart ${ }^{10}$. The aim of this study is to compare the clinical outcome between the patients of anterior and inferior wall myocardial infarction in our tertiary care set up.

\section{METHODOLOGY}

A comparative cross sectional study was conducted on 340 patients (208 patients with AWMI and 132 patients with IWMI who presented with Acute ST-Elevation MI) to emergency department of Armed Forces Institute of Cardiology / National Institute of Heart Disease during specified period. Outcome was calculated using ECG (Electrocardiogram), Two-dimensional transthoracic echocardiogram, Troponin- I, baseline investigations and Coro angiography. Patients fulfilling the inclusion criteria were selected after obtaining their informed written consent. Detailed history of coronary artery disease and its co-morbidwere recorded with the help of prevalidated, semi-structured case record Performa. 
Patients were followed for clinical outcome in adult cardiology wards till hospital admission. Inclusion criteria was all patients presenting with chest pain consistent with acute myocardial infarction of less than 12 hours duration, electrocardiography changes i.e, ST-segment elevation in leads II,III and AVF and in leads I, AvL, V1-V6, new or presumably new left bundle branch block on electrocardiogram, patients with complica- ptoms chest pain was highest $25571.4 \%$ followed by diaphoresis $55(15.4 \%)$ and breathlessness 51 $(14.3 \%)$. Percutaneous intervention was done in $116(32.5 \%)$ parients. Similarly CPR was done in 9 patients $9(2.5 \%)$. The most common complications in patients with inferior wall MI were Brady arrhythmia $8(2.3 \%)$ whereas left ventricular failure $41(12.1 \%)$ was more prevalent in patients with anterior wall MI after TVCAD. The results

Table: Clinical characteristics of patients presenting with acute myocardial infarction.

\begin{tabular}{|c|c|c|}
\hline \multicolumn{2}{|l|}{ Variables } & Frequency (\%) \\
\hline \multirow{6}{*}{ Age } & (Mean \pm SD) & $59.38 \pm 12.912$ years \\
\hline & Age groups & \\
\hline & 21-38 years & $18(5.0 \%)$ \\
\hline & 39-57 years & $137(37.4 \%)$ \\
\hline & $58-75$ years & $161(45.1 \%)$ \\
\hline & $>76$ years & $37(10.4 \%)$ \\
\hline \multirow{2}{*}{ Gender } & Male & \\
\hline & Female & \\
\hline \multirow{6}{*}{ Presenting Symptoms } & Chest pain & $255(71.4 \%)$ \\
\hline & Breathlessness & $51(14.3 \%)$ \\
\hline & Sweating & $55(15.4 \%)$ \\
\hline & Jaw pain & $2(0.6 \%)$ \\
\hline & Epigastric pain & $10(2.8 \%)$ \\
\hline & Shoulder pain & $2(0.6 \%)$ \\
\hline \multirow{4}{*}{ Heart failure } & KILLIP class 1 & $290(81.2 \%)$ \\
\hline & KILLIP class 2 & $59(16.5 \%)$ \\
\hline & KILLIP class 3 & $7(2.0 \%)$ \\
\hline & KILLIP class 4 & $1(0.3 \%)$ \\
\hline \multicolumn{2}{|l|}{ CPR done in ER } & $9(2.5 \%)$ \\
\hline \multirow{3}{*}{ Intervention } & Previous CABG & $4(1.1 \%)$ \\
\hline & Prior PCI & $1(0.3 \%)$ \\
\hline & Primary PCI & $116(32.5 \%)$ \\
\hline
\end{tabular}

tions secondary to AWMI or IWMI. Exclusion criteria waspatients with chest pain but not meeting the criteria of anterior or inferior wall MI, patients with Acute MI other than anterior and inferior wall MI, hyperkalemia and Brugada syndrome ${ }^{4,11}$. All the data was handled with care to maintain patient confidentiality.

\section{RESULTS}

Among the variables, mean age was $59.38 \pm$ 12.91 in each group. Most of the patients were in the range of 58-75 years of age 161 (45.1\%) whereas; only $18(5 \%)$ of the total patients were present in the range of 21-38 years of age. In clinical sym- of cardiogenic shock $5(1.5 \%)$, ventricular tachycardia $3(0.8 \%)$ in inferior wall myocardial infarction were comparative to the results of cardiogenic shock 18(5.3) ventricular tachycardia 2 (0.5\%) in anterior wall myocardial infarction. The number of stable patients was $91(43.7 \%)$ in AWMI and $51(38.6 \%)$ in IWMI. TVCAD in the IWMI was 25 (18.9\%) whereas; in AWMI, it was 35(17\%) as shown in table \& figure.

\section{DISCUSSION}

In this analysis of our study, we showed that patients with an inferior AMI are more likely to develop AV nodal conduction abnormalities such 
as AV blocks, while those patients with an anterior AMI are more likely to develop ventricular tachyarrhythmia. In a study by Rathore et al, the incidence of complete AV block among patients with inferior AMI was twice as high when compared to patients with an anterior AMI. On the other hand, there is no consensus in the literature on the association between AMI location and ventricular tachyarrhythmia ${ }^{12}$. While our data

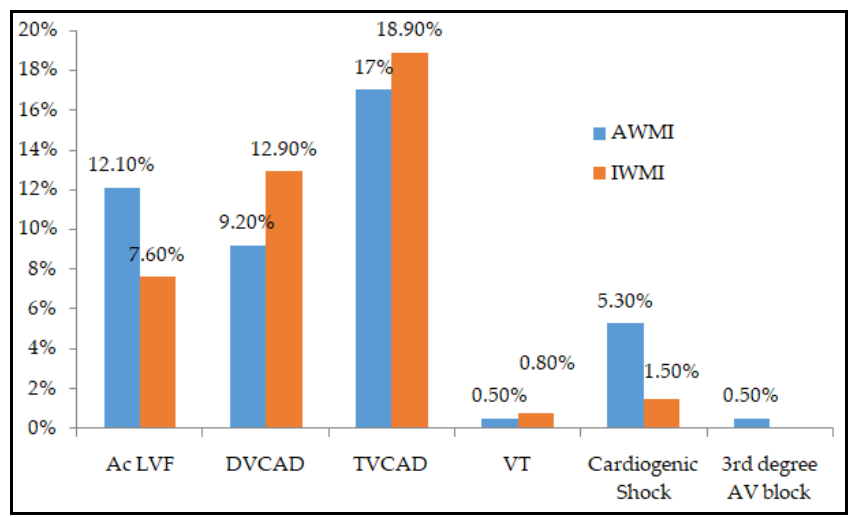

Figure: Comparison of clinical outcome of patients of AWMI versus IWMI.

have shown an association between ventricular tachyarrhythmia and anterior AMI, which may be explained on the basis of the larger myocardial mass involved with these AMI locations; a study by Henriques et al, revealed the same ${ }^{13}$. Our study showed that despite the fact that left main lesion was similar in the two types of myocardial infarction, the number of involved coronary arteries was significantly higher in the inferior myocardial infarction patients. It has been suggested that each site of acute myocardial infarction has relatively specific mechanisms so that predominant pathophysiology in inferior infarction can be vasoconstriction and in anterior infarction can be advanced atherosclerotic process ${ }^{10}$. A prob-able explanation for this finding may be the fact that our results was obtained based on our angiographic database and maybe the patients with inferior wall myocardial infarction who referred for angiography to our center had high risk features and did not include all the inferior myocardial infarction population. Another important finding in our study was more common use of primary PCI protocol in patients with anterior wall myocardial infarction. In a study by Solodky et al, patients with anterior wall myocardial infarction allocated to primary PCI had better clinical outcomes than patients with other types of myocardial infarction and this result was clearer in young patients. Previous randomized trials have established the superiority of PCI over fibrinolytic treatment in patients with myocardial infarction, especially in anterior wall involvement ${ }^{14}$. Congestive heart failure occurred with comparable frequency in patients with inferior myocardial infarction, but was significantly more common in patients with anterior infarction. Hypotension, defined as a systolicarterial blood pressure of less than $90 \mathrm{~mm} \mathrm{Hg}$ in the presence of normal sinus rhythm, occurred with comparable frequency in the these groups ${ }^{15-17}$. We found that patients with IMI had a better in-hospital prognosis than those with AMI. They had a significantly lower mortality rate and significantly lower prevalence of poor left ventricular function (congestive heart failure and cardiogenic shock) and conduction defects (RBBB, LAHB and IVCD) but patients with anterior AMI still had higher in-hospital mortalityand morbidity. Our findings are in agreement with those of Strauss et al, who demonstrated a better prognosis of patients with IMI than those with AMI suffering a similar degree of myocardial injury ${ }^{18}$. Thus, the MI location itself may independently affect the prognosis. Bulkley suggested thatthe intrinsic and extrinsic qualitative differences between the anterior and inferior wall might have contributed to this different outcome ${ }^{19}$.

The present study has several important limitations. First, this is a single center study; therefore, its results cannot be generalized because there is a great difference of in hospital patient care in different set ups. Second, Most of the patients were discharged from the hospital soon after thrombolysis or primary percutaneous intervention, and were not followed for further clinical outcomes therefore long-term clinical outcome results could not be accurately obtained. The other reason is that this is a short duration study of four months, but this study requires a 
long term follow up which was not done. Third most of the data wasderived either from hospital discharge books which may also show observer or technical errors. Therefore, it is very important to further probe into the data and patients should be followed up for long term clinical outcome.

\section{CONCLUSION}

The study shows the comparative clinical outcome of anterior wall myocardial infarction versus inferior wall myocardial infarction.

\section{CONFLICT OF INTEREST}

This study has no conflict of interest to be declared by any author.

\section{REFERENCES}

1. Afreen A, Khan MN, Khan MB, Ahmad A, Akbar MS, Danyal SM. S82 Risk factor assessment in patients undergoing coronary angiography at army cardiac centre lahore. Pak Arm For Med J 2019; 69(Suppl-1): S82-86.

2. Burke AP, Farb A, Pestaner J. Traditional risk factors and the incidence of sudden coronary death with and without coronary thrombosis in blacks. Circulation 2002; 105(4): 419-24.

3. Pearson TA, Blair SN, Daniels SR, Eckel RH, Fair JM, Fortmann $\mathrm{SP}$, et al. AHA guidelines for primary prevention of cardiovascular disease and stroke: 2002 update: consensus panel guide to comprehensive risk reduction for adult patients without coronary or other atherosclerotic vascular diseases. Circulation 2002; 106(3): 388-91.

4. Ryan TJ, Melduni RM. Highlights of latest American College of Cardiology and American Heart Association guidelines for management of patients with acute myocardial infarction. Cardiology Review 2002; 10(1): 35-43.

5. Thanavaro S, Kleiger RE, Province MA, Hubert JW, Miller JP, Krone RJ, et al. Effect of infarct location on the in-hospital prognosis of patients with first transmural myocardial infarction. Circulation 1982; 66(4): 742-47.

6. Hutter Jr AM, De Sanctis RW, Flynn T, Yeatman LA. Nontransmural myocardial infarction: a comparison of hospital and late clinical course of patients with that of matched patients with transmural anterior and transmural inferior myocardial infarction. Am J Cardiol 1981; 48(4): 595-02.

7. Rosamond WD, Chambless LE, Folsom AR, Cooper LS, Conwill $\mathrm{DE}$, Clegg L, et al. Trends in the incidence of myocardial infarction and in mortality due to coronary heart disease, 1987 to 1994.
N Engl J Med 1998; 339(13): 861-65.

8. Lie KI, Sokole EB, Res J, Van Der Schoot JB, Durrer D. Prevalence of right ventricular involvement in inferior wall infarction assessed with myocardial imaging with thallium-201 and technetium-99m pyrophosphate. Am J Cardiol 1978; 42(3): 358-62.

9. Gupta PK, Lichstein E. Heart block complicating acute inferior wall myocardial infarction. Chest 1976; 69(5): 599-604.

10. Kazazi EH, Sheikhvatan M, Mahmoodian M, Fathollahi MS, Sadeghian $\mathrm{H}$. Comparing angiography features of inferior versus anterior myocardial infarction regarding severity and extension in a cohort of Iranian patients. Journal of research in medical sciences: the official. J Isfahan Uni Med Scien 2011; 16(4): 484-88.

11. Eskola MJ, NIkus KC, Homvang L. Value of 12 lead ECG to define the level of obstruction in acute anterior MI: correlation to CAG and clinical outcome in DANAMI-2 trail. Int J cardiol 2009; 131(3): 378-83.

12. Rathore SS, Gersh BJ, Berger PB, Weinfurt KP, Oetgen WJ, Schulman KA, et al. Acute myocardial infarction complicated by heart block in the elderly: prevalence and outcomes. Am Heart J 2001; 141(1): 47-54.

13. Gheeraert PJ, Henriques JP, De Buyzere ML, De Pauw M, Taeymans Y, Zijlstra F. Preinfarction angina protects against out-of-hospital ventricular fibrillation in patients with acute occlusion of the left coronary artery. J Am Coll Cardiol 2001; 38(5): 1369-74.

14. Solodky A, Assali AR, Behar S, Boyko V, Battler A, Kornowski $\mathrm{R}$. Anterior wall myocardial infarction in real world: Does reperfusion strategy make any differences?. Cathet Cardiovasc Intervent 2004; 61(1): 79-83.

15. Wolk MJ, Scheidt S, Killip T. Heart failure complicating acute myocardial infarction. Circulation 1972; 45(5): 1125-38.

16. Wu AH, Parsons L, Every NR, Bates ER. Hospital outcomes in patients presenting with congestive heart failure complicating acute myocardial infarction: a report from the Second National Registry of Myocardial Infarction (NRMI-2). J Am Coll Cardiol 2002; 40(8): 1389-94.

17. Rigo PI, Murray MA, Taylor DR, Weisfeldt ML, Strauss HW, Pitt BE. Hemodynamic and prognostic findings in patients with transmural and nontransmural infarction. Circulation 1975; 51(6): 1064-70.

18. Becker LC, Silverman KJ, Bulkley BH, Kallman CH, Mellits ED, Weisfeldt MY. Comparison of early thallium-201 scintigraphy and gated blood pool imaging for predicting mortality in patients with acute myocardial infarction. Circulation 1983; 67(6): 1272-82.

19. Naqvi MA, Ali M, Hakeem F, Masood A, Akram Z. Correlation of severity of ST segment elevation in acute inferior wall myocardial infarction with the proximity of right coronary artery disease. J Ayub Med Coll Abbottabed 2008; 20(4): 1-4. 